\title{
Effects of sulfur dioxide, ozone, and ambient air pollution on bone metabolism related biochemical parameters in a rat model
}

\author{
Sorayya Kheirouri 1(D), Mohammad Alizadeh 2(D), Razieh Musapour Sultan Abad ${ }^{3}$, Sona Barkabi-Zanjani ${ }^{4}$, Mehran \\ Mesgari-Abbasi 5(D)* \\ ${ }^{1}$ Department of Nutrition, Tabriz University of Medical Sciences, Tabriz, Iran. \\ ${ }^{2}$ Nutrition Research Center, Tabriz University of Medical Sciences, Tabriz, Iran. \\ ${ }^{3}$ Student Research Committee, Tabriz University of Medical Sciences, Tabriz, Iran. \\ ${ }^{4}$ Department of Physiology, Faculty of Medicine, Tabriz University of Medical Sciences, Tabriz, Iran. \\ ${ }^{5}$ Drug Applied Research Center, Tabriz University of Medical Sciences, Tabriz, Iran.
}

*Correspondence: mesgarim@tbzmed.ac.ir

Received: July 08, 2020 Accepted: October 10, 2020

\begin{abstract}
Ambient air pollution (AAP), as an important environmental health problem, affects everyone. A large body of literature links AAP, such as sulfur dioxide $\left(\mathrm{SO}_{2}\right)$ and ozone $\left(\mathrm{O}_{3}\right)$, with a wide range of non-communicable diseases. The aim of the present study was to investigate the effects of the pollutants on the bone metabolism biochemical parameters in a rat model. Thirty-two male Wistar rats were divided to four groups: control, $\mathrm{SO}_{2}$ (10 ppm), $\mathrm{O}_{3}(0.6 \mathrm{ppm})$, and AAP groups. After 5 weeks of exposure ( 3 hours/day, 6 days/week), blood samples were taken, and biochemical parameters were assayed. Vitamin D level of the AAP group was higher than the control and $\mathrm{SO}_{2}$ groups ( $\mathrm{p}=0.004$ and 0.003 ). Parathyroid hormone $(\mathrm{PTH})$ level of the $\mathrm{O}_{3}$ group was significantly higher than the AAP group $(\mathrm{p}=0.006)$. Alkaline phosphatase (ALP), phosphorus, magnesium levels of the $\mathrm{SO}_{2}$ group; Vit $\mathrm{D}, \mathrm{ALP}$, osteocalcin (OC), and $\mathrm{PTH}$ of $\mathrm{O}_{3}$ group; and $\mathrm{OC}$ and osteoprotegerin (OPG) of AAP group were higher than those of control group but differences were not significant. Calcium level of the $\mathrm{SO}_{2}$ group; OPG and calcium of $\mathrm{O}_{3}$ group; and PTH of AAP group were less than those of control group but differences were not significant $(\mathrm{p}>0.05)$. The results showed significant effect of AAP with natural daylight on vitamin $\mathrm{D}$ and also $\mathrm{O}_{3}$ on PTH of the rats. In the concentrations and conditions of the study, we didn't find any significant unwanted effects of $\mathrm{AAP}, \mathrm{SO}_{2}$, and $\mathrm{O}_{3}$ on the bone biochemical parameters. More investigations with more concentrations and exposure time are recommended.
\end{abstract}

Keywords: Air pollution, bone, ozone, rats, sulfur dioxide, Vitamin D

\section{Introduction}

Ambient (outdoor) air pollution, as an important environmental health problem, affects everyone in low-, middle-, and high-income countries. It was estimated that ambient air pollution (AAP) caused 4.2 million premature deaths worldwide in both cities and rural areas in 2016. In the same year, $91 \%$ of the world population was living in the places that the world health organization (WHO) air quality guidelines levels were not met. People of low- and middle-income countries unfortunately, experience the burden of AAP with $91 \%$ of the premature deaths [1].

The major indicators of air pollution are particulate matter $(\mathrm{PM})$, ozone $\left(\mathrm{O}_{3}\right)$, sulfur dioxide $\left(\mathrm{SO}_{2}\right)$, and nitrogen dioxide $\left(\mathrm{NO}_{2}\right)$. Serious risks to health are produced not only from exposure to $\mathrm{PM}$, but also from exposure to $\mathrm{SO}_{2}, \mathrm{O}_{3}$, and $\mathrm{NO}_{2}[1]$.

$\mathrm{O}_{3}$ at ground level is formed by the photochemical reaction (reaction with sunlight) of pollutants such as NOx from vehicle and industry emissions and volatile organic compounds emitted by vehicles, solvents and industry. Therefore, the highest levels of $\mathrm{O}_{3}$ pollution occur during periods of sunny weather [1]. $\mathrm{SO}_{2}$ is a colorless gas with a sharp odor. The main anthropogenic source of $\mathrm{SO}_{2}$ is produced from the burning of sulfur-containing fossil fuels (oil, coal) and the smelting of mineral ores that contain sulfur for heating, motor vehicles, and power generation. Recent evidences show that much lower levels of $\mathrm{SO}_{2}$ (than previously believed) are associated to health effects and reducing $\mathrm{SO}_{2}$ concentrations is likely to decrease exposure to co-pollutants [1].

Air quality guideline values have been established based on expert evaluation of current scientific evidences by WHO. The guideline values are presented in Table 1 [2]. 
Table 1. The mean concentrations of ambient air pollution (AAP) parameters reported by Iranian air pollution monitoring system for Tabriz Abresan station during the study 5 weeks, and air quality guideline by World Health Organization (WHO). $(2,12) \mathrm{SO}_{2}$ : sulfur dioxide; $\mathrm{CO}$ : carbon monoxide; $\mathrm{NO}_{2}$ : nitrogen dioxide; $\mathrm{O}_{3}$ : ozone; PM: particulate matter. Data are presented as mean \pm standard deviation.

\begin{tabular}{|c|c|c|c|c|c|c|c|}
\hline \multicolumn{2}{|c|}{ Concentration $\left(\mu \mathrm{g} / \mathrm{m}^{3}\right)$} & $\mathrm{SO}_{2}$ & $\mathrm{CO}$ & $\mathrm{NO}_{2}$ & $\mathrm{O}_{3}$ & $\mathbf{P M}_{2.5}$ & $\mathrm{PM}_{10}$ \\
\hline \multicolumn{2}{|c|}{ Ambient air concentration } & $2.00 \pm 1.17$ & $14.08 \pm 10.07$ & $23.96 \pm 8.26$ & $49.76 \pm 18.48$ & $28.67 \pm 4.04$ & $21.33 \pm 5.13$ \\
\hline \multirow{5}{*}{$\begin{array}{c}\text { WHO } \\
\text { guideline }\end{array}$} & 10-minute mean & 500 & - & - & - & - & - \\
\hline & 1-hour mean & - & - & 200 & - & - & - \\
\hline & 8-hour mean & - & - & - & 100 & - & - \\
\hline & 24-hour mean & 20 & - & - & - & 25 & 50 \\
\hline & Annual mean & - & - & 40 & - & 10 & 20 \\
\hline
\end{tabular}

A large body of literatures links AAP with a wide range of non-communicable diseases [5, 6]. Osteoporosis is characterized by bone mass content and tissue micro-architectural decreasing. That is a result of cumulative factors affecting bone health $[5,6]$. In the last few decades, an increase in the prevalence of osteoporosis is reported by several studies and organizations that may resulted in increasing the risk of subsequent osteoporotic fractures [7].

The prevalence of vitamin D (Vit D) deficiency, osteopenia, and osteoporosis in Iran is high [8]. The prevalence of them is higher in the northern regions of Iran. It is estimated that 35 and $17 \%$ of general population of Iran aged $>30$ years have osteopenia and osteoporosis, respectively. The Iranian Multicenter Osteoporosis Study (IMOS) reported that more than two-thirds of women and half of men over the age of 50 have a low bone mineral density [9, 10]. Osteoporotic fractures represent an enormous public health burden [8]. In recent years, the increasing trend of the diseases is promising a critical public health problem in Iran [11]. Vit D deficiency, disorders of calcium balance, and hyperparathyroidism are causes of osteoporosis [8].

Evidences evaluating the association between AAP and bone health related biochemical factors is limited [4]. Some previous studies have concluded associations between air pollution and bone mineral density loss and increased risk of osteoporotic fracture [12, 13]. Evidence from some previous studies indicate that air pollutants, including several components, are in relationship with induction of an oxidative stress followed by low-grade systemic inflammatory state. That can result in endocrine disruption and Vit D metabolism changes. The changes may have potential effects on bone homeostasis parameters. But some other studies reported no association [14, 15].

To our knowledge, there is no animal study evaluating the effects of AAP on bone health related biochemical parameters. Our objective was to evaluate the effects of AAP of Tabriz city, the capital and industrial city of north-west of Iran, and also $\mathrm{SO}_{2}$, and $\mathrm{O}_{3}$, separately, on bone related biochemical factors including Vit $\mathrm{D}$, parathyroid hormone (PTH), osteocalcin (OC), osteoprotegerin (OPG), alkaline phosphatase (ALP), phosphorus, magnesium, and calcium using a rat animal model.

\section{Material and Methods}

\section{Animals}

Thirty-two male Wistar rats (200 \pm 20 g) were purchased from Pasteur Institute (Karaj, Iran) and maintained under standard conditions $\left(22 \pm 2{ }^{\circ} \mathrm{C}, 12 / 12\right.$ hours light/dark cycle, and $50-70 \%$ humidity). The water and food were ad libitum. The animals were adapted to the conditions mentioned above for one week, before experimentation.

All the procedures were approved by the Research Ethics Committee of Tabriz University of Medical Sciences (IR.TBZMED.REC.1396.1195) and were performed in accordance with the approved proposal.

\section{Procedures}

The animals were randomly divided into 4 groups $(n=8)$ as follows:

- The control group was placed under filtered air condition in standard cages in animal room.

- The $\mathrm{SO}_{2}$ group, exposed to $10 \mathrm{ppm} \mathrm{SO}$ for 5 weeks ( 3 hours/day, 6 days/week). A chamber-house was made of glass $\left(60 \times 50 \times 40 \mathrm{~cm}^{3}\right)$ and equipped with two top and bottom output for ventilation. $\mathrm{SO}_{2}$ in the exposure chamber was provided by $2 \times 50$ - $\mathrm{L}$ cylinders (120 bar pressure, $20 \mathrm{ppm} \mathrm{SO}_{2}$ ). The mixed gases composition of the chamber was: $\mathrm{SO}_{2}(0.002 \%), \mathrm{O}_{2}(20.5 \%)$ and $\mathrm{N}_{2}(79.5 \%)$, and the flow rate was $11 / \mathrm{min}$. The $\mathrm{SO}_{2}$ concentration of the chamber was daily measured by $\mathrm{SO}_{2}$ detector tube (GASTEC No.5La; measuring range 2-30 ppm).

- The $\mathrm{O}_{3}$ group, exposed to $0.6 \pm 0.1 \mathrm{ppm} \mathrm{O}$ for 5 weeks ( 3 hours/day, 6 days/week) in a chamber-house described before. The $\mathrm{O}_{3}$ was produced by an $\mathrm{O}_{3}$ producer system. The $\mathrm{O}_{3}$ concentration of the chamber was daily (measured by $\mathrm{O}_{3}$ detector (A-21ZX/USA). 
- The AAP group, placed in the Tabriz (East Azerbaijan, Iran) high traffic city center (Abresan square) near Abresan air pollution recorder station 3 hours/day, 6 days/week for 5 weeks. The AAP report of Iranian air pollution monitoring system in the period of the time are shown in Table 1 [16].

Twenty hours after the last exposure, blood samples were obtained by cardiac puncture under anesthetic condition (Ketamine/Xylazine, 60/10 mg/kg IP) [17]. The samples were centrifuged at $3000 \mathrm{~g}\left(4^{\circ} \mathrm{C}, 10 \mathrm{~min}\right)$. The blood serum samples were maintained in $-70{ }^{\circ} \mathrm{C}$ deep freezer until use.

\section{Biochemical analyses}

The calcium, magnesium, phosphorus, and ALP of blood serum samples were assayed by enzymatic methods using commercial kits (Pars Azmun, Karaj, Iran). The automated Abbott biochemistry analyzer (Alcyon 300, USA) was used for the analysis. The Vit D, PTH, OC, and OPG of blood samples were determined by enzyme-linked immunosorbent assay (ELISA) method using rat commercial ELISA kits (Eastbiopharm, Hangzhou, China) and Awareness ELISA plate reader (Statfax 2100, USA)

\section{Statistical analyses}

Statistical analyses were performed using Statistical Package for the Social Sciences (SPSS version 13) for Windows (SPSS Inc., Chicago, IL, USA). One-way analysis of variance (ANOVA) was used to compare parameters between the groups, followed by multiple comparisons with the Tukey post-hoc test. The data were expressed as mean \pm standard deviation (SD). p-values less than 0.05 were considered statistically significant.

\section{Results}

\section{Effects of ambient air pollution (AAP) exposure}

Our findings indicate no obvious difference of the blood serum concentrations of the OC and OPG (Figure 1) between AAP and control groups ( $\mathrm{p}>0.05$ ). ALP (Figure 2), phosphorous, magnesium, and calcium (Figure 3) serum concentrations of the rats in the AAP group were higher and the PTH (Figure 4) concentrations were lower than the control group but the differences were not statistically significant ( $>>0.05)$. The Vit D (Figure 1) level of the AAP group was significantly higher than the control and $\mathrm{SO}_{2}$ groups ( $\mathrm{p}=0.004$ and 0.003 , respectively).

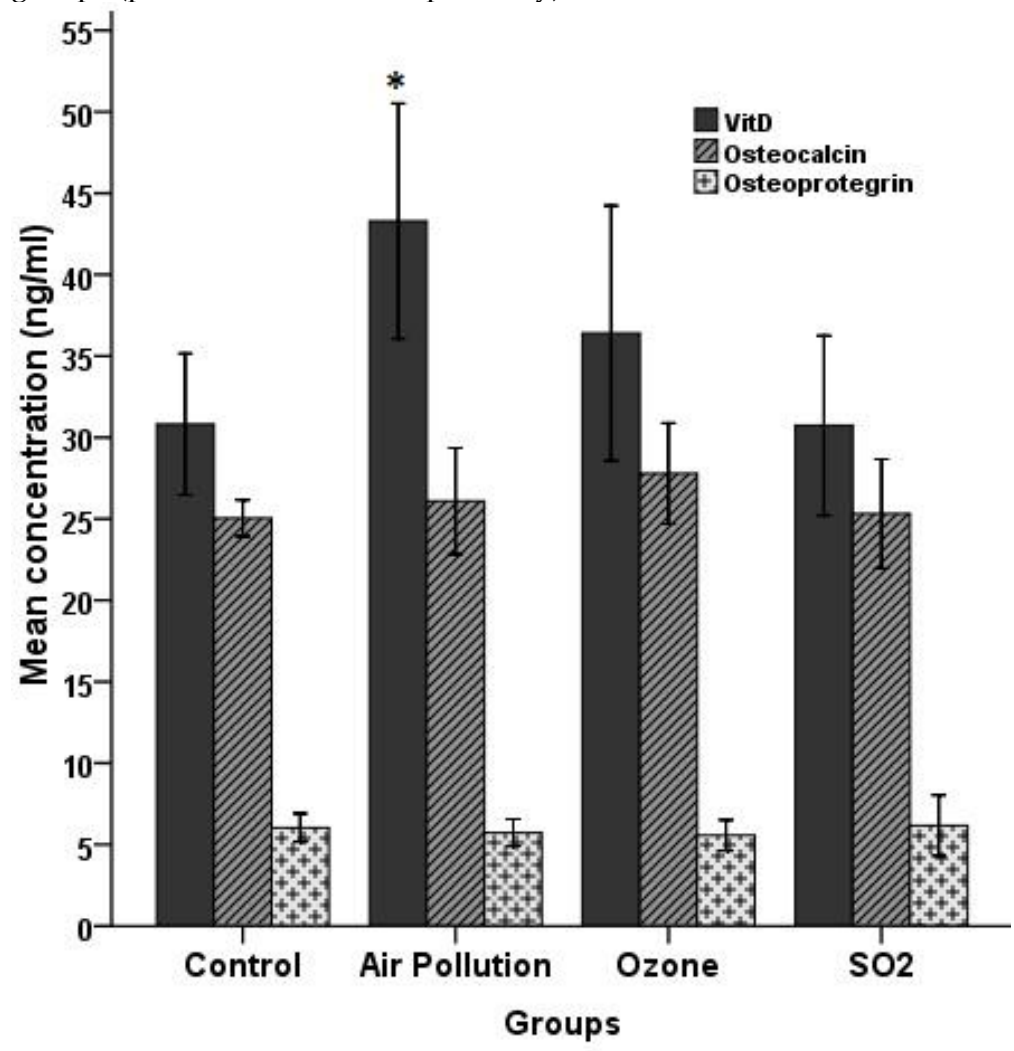

Figure 1. Effects of $\mathrm{SO}_{2}$ (sulfur dioxide; $10 \mathrm{ppm}$ ), $\mathrm{O}_{3}$ (ozone; $0.6 \mathrm{ppm}$ ), and ambient air pollution (AAP) inhalation (for 5 weeks) on blood serum level of Vitamin D (Vit D), osteocalcin (OC), and osteoprotegerin (OPG) of the rats $(\mathrm{n}=8)$. Data are presented as mean \pm standard deviation. ${ }^{*} \mathrm{p}<0.05$ 


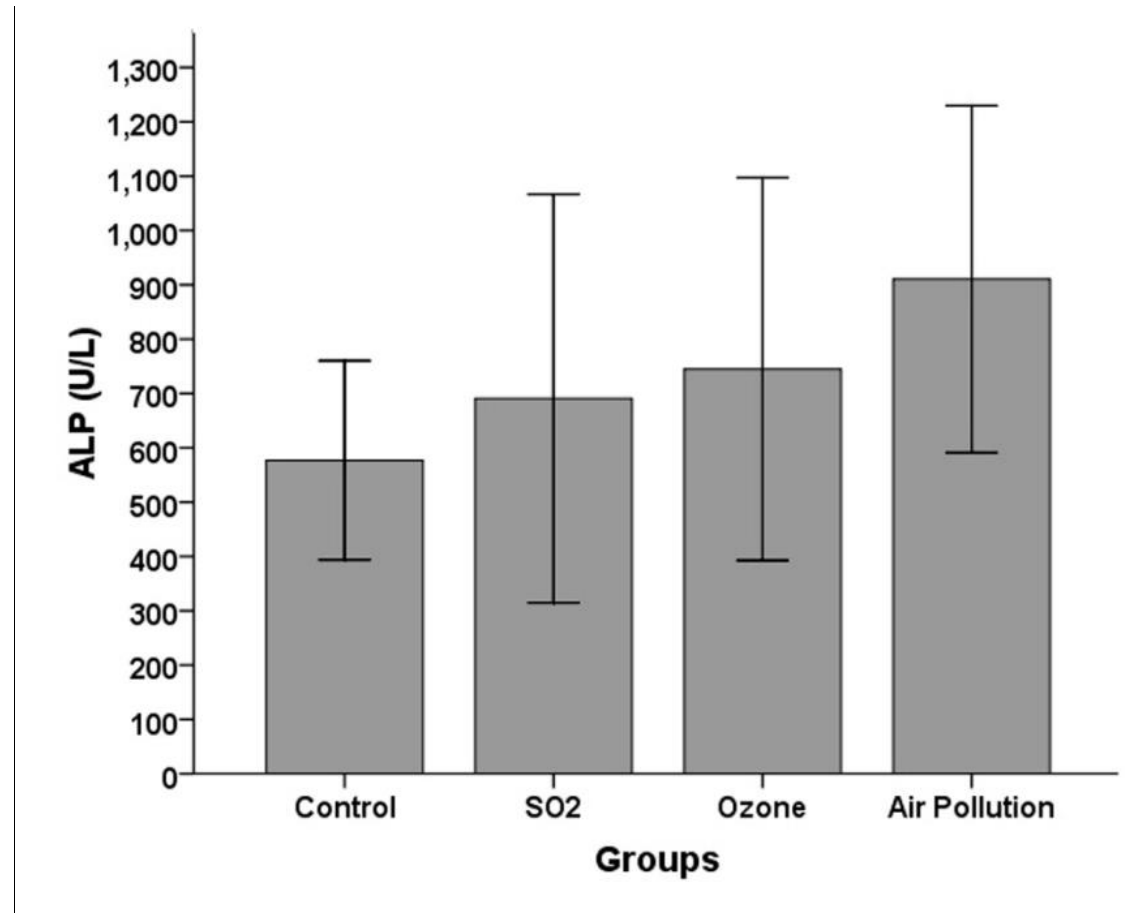

Figure 2. Effects of $\mathrm{SO}_{2}$ (sulfur dioxide; $10 \mathrm{ppm}$ ), $\mathrm{O}_{3}$ (ozone; $0.6 \mathrm{ppm}$ ), and ambient air pollution (AAP) inhalation (for 5 weeks) on blood serum level of alkaline phosphatase (ALP) of the rats ( $n=8)$. Data are presented as mean \pm standard deviation .

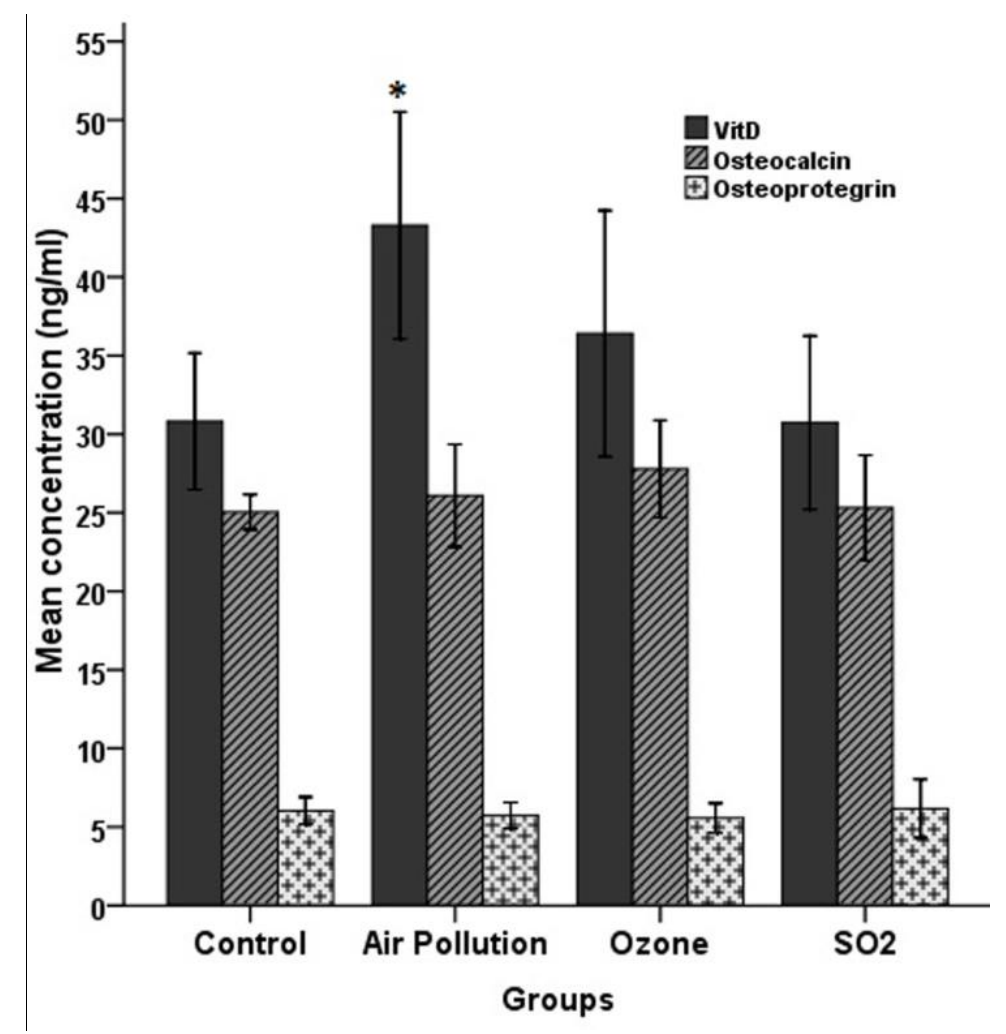

Figure 3. Effects of $\mathrm{SO}_{2}$ (sulfur dioxide; $10 \mathrm{ppm}$ ), $\mathrm{O}_{3}$ (ozone; $0.6 \mathrm{ppm}$ ), and ambient air pollution (AAP) inhalation (for 5 weeks) on blood serum level of calcium, phosphorous, and magnesium of the rats $(n=8)$. Data are presented as mean \pm standard deviation . 


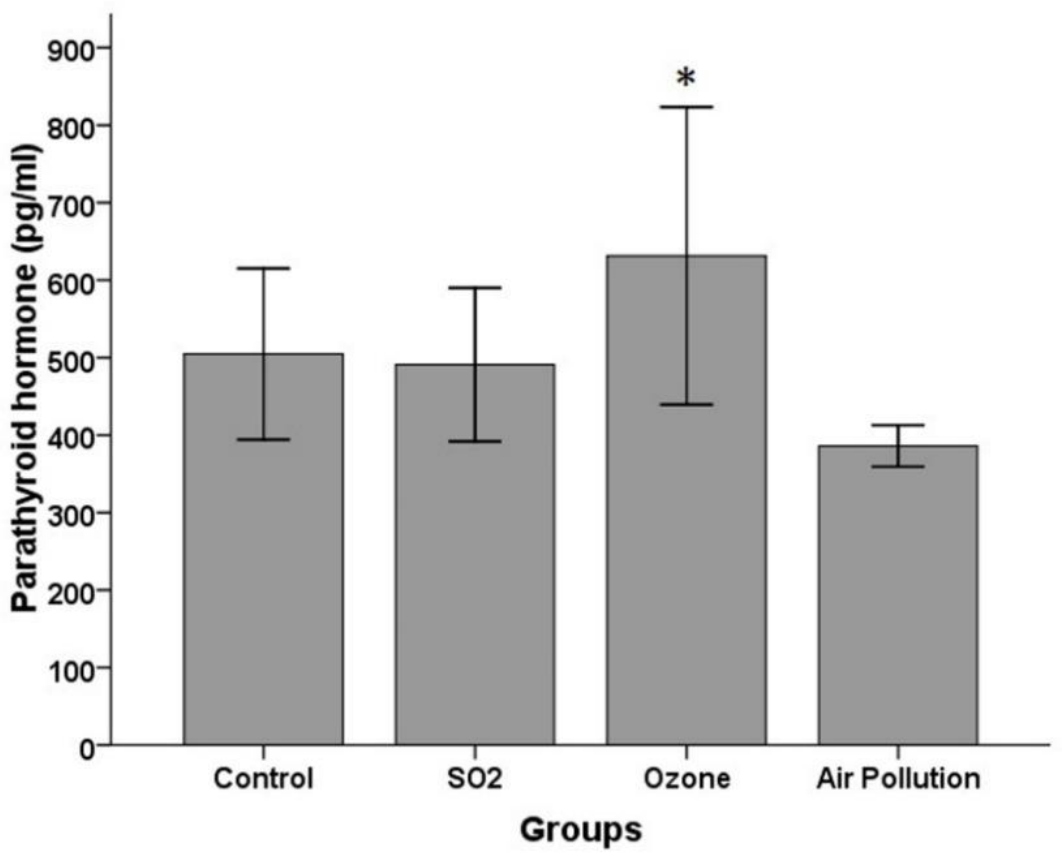

Figure 4. Effects of $\mathrm{SO}_{2}$ (sulfur dioxide; $10 \mathrm{ppm}$ ), $\mathrm{O}_{3}$ (ozone; $0.6 \mathrm{ppm}$ ), and ambient air pollution (AAP) inhalation (for 5 weeks) on blood serum level of parathyroid hormone (PTH) of the rats $(n=8)$. Data are presented as mean \pm standard deviation. ${ }^{*} \mathrm{p}<0.05$

\section{Effects of sulfur dioxide $\left(\mathrm{SO}_{2}\right)$ exposure}

Our results didn't show any considerable difference of the blood serum concentrations of OC, OPG, Vit D (Figure 1), and PTH (Figure 4) between $\mathrm{SO}_{2}$ and control groups (p>0.05). The ALP (Figure 2), phosphorous, and magnesium (Figure 3) serum concentrations of the rats in the $\mathrm{SO}_{2}$ group were higher and the calcium (Figure 3) concentration was lower than the control group but the differences were not statistically significant $(p>0.05)$.

\section{Effects of ozone $\left(\mathrm{O}_{3}\right)$ exposure}

Our results indicate no considerable difference of the blood serum concentrations of phosphorous and magnesium (Figure 3) between $\mathrm{O}_{3}$ and control groups ( $\left.\mathrm{p}>0.05\right)$. The OC, Vit D (Figure 1), ALP (Figure 2), and PTH (Figure 4) serum concentrations of the rats in the $\mathrm{O}_{3}$ group were higher and the OPG (Figure 1) and calcium (Figure 3) concentrations were lower than the control group but the differences were not statistically significant $(\mathrm{p}>0.05)$. The $\mathrm{PTH}$ level of the $\mathrm{O}_{3}$ group was significantly higher than the air pollution group $(\mathrm{p}=0.006)$.

\section{Discussion}

Polluted air has different compositions in different cities and also in different times of the day and during a week because of different sources, frequencies, and amounts of air pollutants. Therefore, each study about AAP is a unique study with unique air pollutants. The AAP of our investigation were not comparable with the most polluted cities in the world but it was considerable (Table 1). Tabriz city is one of the most polluted cities in Iran with 1.559 million (2016) population.

\section{Effects of ambient air pollution (AAP)}

Surprisingly, our results showed significant increase in Vit D level of air pollution group in compare to the control group (Figure 1). The finding is in opposite to findings of the previous human studies. In one of the studies, air pollution had decreasing effects on Vit D levels [18]. They stated that the $\mathrm{AAP}\left(\mathrm{O}_{3}\right.$ and $\left.\mathrm{PM}\right)$ presents a physical barrier to solar ultraviolet B (UV-B) radiation [19], thereby contributing to lower cutaneous production of Vit D [14, 20, 21].

The mean calcium, magnesium, phosphorus, and ALP levels of air pollution group blood samples were increased in comparison with control group, but they weren't statistically significant $(p>0.05)$ (Figure 2 and Figure 3) that may be because of Vit D increasing effects. Vit D is responsible for increasing intestinal absorption of calcium, magnesium, and phosphate [22].

The PTH level of blood serum in AAP group was decreased in comparison with control group, but it wasn't significant ( $p>0.05$ ) (Figure 4). It may be because of the increase of blood Vit D and calcium as regulatory feedback. One of the roles of Vit D is to maintain skeletal calcium balance by promoting calcium absorption in the intestines, promoting bone 
resorption by increasing osteoclast number, and maintaining calcium and phosphate levels for bone formation. The procedure affects and allows proper functioning of PTH to maintain serum calcium levels [23]. A study in the United States found an association between 1-year residential concentration of ambient PM2.5 and black carbon and lower serum PTH levels [24]. (Figure. 1).

There weren't considerable differences between blood samples OC and OPG in the control and AAP groups

The major natural source of Vit D is the synthesis of cholecalciferol in the lower layers of skin epidermis. The chemical reaction is dependent on sun exposure (specifically UV-B radiation) [25]. In our study, only the AAP group was located in the exposure to the natural day-light and the other rats, including the control ones, were in animal room away from natural day-light. Although the rats of the AAP group were not in direct sun-light, they received indirect sunlight. It may be the reason for the more synthesis of Vit D in their body. It may have resulted that in the condition of our study the positive effect of ambient natural daylight on Vit D level of the rats was more effective than negative effect of air pollution.

\section{Effects of sulfur dioxide $\left(\mathrm{SO}_{2}\right)$}

Our findings showed no considerable effects of the $10 \mathrm{ppm} \mathrm{SO}_{2}$ intervention on the Vit D, PTH, OC, and OPG levels of blood serum in comparison with those of the control group (Figure 1 and Figure 4). The mean calcium content in blood serum was less and ALP, phosphorus, and magnesium levels were higher in $\mathrm{SO}_{2}$ group rats comparing to the control group but the differences weren't statistically significant ( $>0.05)$ (Figure 2 and Figure 3 ).

\section{Effects of ozone $\left(\mathrm{O}_{3}\right)$}

The findings showed a decreasing effect of $0.6 \pm 0.1 \mathrm{ppm} \mathrm{O}_{3}$ on the calcium and OPG levels of blood serum in the $\mathrm{O}_{3}$ group rats in comparison with those in the control group (Figure 1 and Figure3), but they weren't statistically significant ( $\mathrm{p}>0.05$ ). The PTH level of the $\mathrm{O}_{3}$ group was significantly higher than that of the control group $(\mathrm{p}<0.05)$ (Figure 4$)$. That may be a result of the decreasing calcium in blood serum. Decreasing of calcium level of plasma results in activating cell surface receptors and the secretion of $\mathrm{PTH}$; it proceeds to stimulate the calcium taking from targeted bone, kidney, and gut cells and entering it into the plasma pool [26].

Results of some previous studies indicated that the PM component of air pollution promotes systemic inflammation and oxidative stress [27], which impair the bone remodeling process [5,28] and indirectly alter bone hormonal homeostasis, such as via PTH [13].

The decrease of the OPG level may be a response to elevating PTH that results in enhancement of osteoclast activation and removing bone calcium to plasma. OPG is an osteoclastogenesis inhibitory factor and also a cytokine receptor. It is a decoy receptor for RANKL in the RANK/RANKL/OPG axis that inhibits osteoclastogenesis and bone resorption [29]. The level of OC, ALP, and Vit $\mathrm{D}$ of $\mathrm{O}_{3}$ group were higher than the control group, but the differences weren't statistically significant ( $\mathrm{p}>0.05)$ (Figure 1 and Figure 2).

In our findings, non-significant increase of OC was obvious in all intervention groups ( $\mathrm{p}>0.05)$ (Figure 1). OC is secreted by osteoblasts and directly binds calcium and concentrates in bone [30]. Previous studies demonstrated that an acute stress response stimulates OC release from bone within minutes in rats [31]. The stress of handling, anesthesia, and sampling may be the reason for increasing blood serum $\mathrm{OC}$ in the groups.

Mean ALP levels in blood serum of AAP, $\mathrm{SO}_{2}$, and $\mathrm{O}_{3}$ groups were higher than those of the control group (p>0.05) (Figure 2). ALP has the physiological role of dephosphorylating compounds. Elevated levels of ALP in different conditions, including bone conditions, osteoblastic bone tumors, osteomalacia, osteoporosis, and hyperparathyroidism were reported. There is a positive correlation between bone formation and serum ALP [32].

\section{Conclusion}

Although results of the present study showed significant effects of AAP and $\mathrm{O}_{3}$ on Vit D and PTH in blood serum of the rats, respectively, overall, in the concentrations and conditions of the study, we didn't find any significant unwanted effects of $\mathrm{AAP}, \mathrm{SO}_{2}$, and $\mathrm{O}_{3}$ on the bone related biochemical parameters in the rats. But the results are not generalizable to human because of metabolic, genetic, and physiological differences between human and rats. On the other hand, it is possible that the concentrations and exposure time of the present study were not enough to make changes in the bone related parameters. Therefore, more investigations with more concentrations and exposure time are recommended to extend our knowledge about that. Study of human osteoporosis and bone related parameters in air polluted and non-polluted areas also may be helpful.

\section{Acknowledgments}


This article is the result of a research project (ID 62144) was financing and conducted at Drug Applied Research Center, Tabriz University of Medical Sciences, Tabriz, Iran. The authors appreciate the financial and instrumental support provided by Drug Applied Research Center of Tabriz University of Medical Sciences, Tabriz, Iran.

\section{Conflict of interest}

Researchers declare that there is no conflict of interest.

\section{CRediT author statement}

MA: Conceptualization, Methodology; MM: Investigation, Writing- Original draft preparation, Funding acquisition; RM: Visualization, Investigation; SB: Visualization, Data curation; SK: Supervision, Writing- Reviewing and Editing.

\section{ORCID}

Sorayya Kheirouri : 0000-0001-6249-4462

Mohammad Alizadeh : 0000-0002-7408-8573

Mehran Mesgari-Abbasi : 0000-0003-0276-930X

\section{References}

[1] World health organization (WHO). Ambient (outdoor) air pollution. [cited 2018 May 2]. Available from: https://www.who.int/news-room/fact-sheets/detail/ambient-(outdoor)-air-quality-and-health

[2] World health organization (WHO). Air quality guidelines for particulate matter, ozone, nitrogen dioxide and sulfur dioxide, Global update 2005, Summary of risk assessment. [cited 2020 Mar 20]. Available from: https://apps.who.int/iris/bitstream/handle/10665/69477/WHO_SDE_PHE_OEH_06.02_eng.pdf;jsessionid=F90A2DC BDBDF4826862FCA4B4DCAC6C6? sequence=1

[3] Ghanbari GM, Mosaferi M, Safari GH, Jaafari J. Effect of exposure to O3, NO2, and SO2 on chronic obstructive pulmonary disease hospitalizations in Tabriz, Iran. Environ Sci Pollut Res 2015;22(4):2817-2823.

[4] Ranzani OT, Milà C, Kulkarni B, Kinra S, Tonne C. Association of ambient and household air pollution with bone mineral content among adults in peri-urban South India. Environ Health 2020;3(1):e1918504.

[5] Eastell R, O'Neill TW, Hofbauer LC, Langdahl B, Reid IR, Gold DT, et al. Postmenopausal osteoporosis. Nat Rev Dis Primers 2016;2(1):16069.

[6] Mora S, Gilsanz V. Establishment of peak bone mass. Endocrinol Metab Clin North Am 2003;32(1):39-63.

[7] Cauley JA. Public health impact of osteoporosis. J Gerontol A Biol Sci Med Sci 2013;68(10):1243-1251.

[8] Larijani B, Resch H, Bonjour JP, Meybodi HA, Tehrani MM. Osteoporosis in Iran, overview and management. Iran J Public Health 2007;36(Supple 1):1-13.

[9] Mirhashemi S, Kalantar Motamedi MH, Mirhashemi AH, Mehrvarz S, Danial Z. Osteoporosis in Iran. HPR 2017;2(2):57"

[10] Rahnavard Z, Zolfaghari M, Hossein-Nezad A, Vahid Dastgerdi M. The incidence of osteoporotic hip fracture: Iranian multicenter osteoporosis study (IMOS). Res J Biol Sci 2009;4(2):171-173.

[11] Irani AD, Poorolajal J, Khalilian A, Esmailnasab N, Cheraghi Z. Prevalence of osteoporosis in Iran: A meta-analysis. J Res Med Sci 2013;18(9):759-766.

[12] Prada D, Zhong J, Colicino E, Zanobetti A, Schwartz J, Dagincourt N, et al. Association of air particulate pollution with bone loss over time and bone fracture risk: analysis of data from two independent studies. Lancet Planet Health 2017;1(8):e337-e347.

[13] Alvaer K, Meyer HE, Falch JA, Nafstad P, Sogaard AJ. Outdoor air pollution and bone mineral density in elderly men: the Oslo Health Study. Osteoporos Int 2007;18(12):1669-1674.

[14] Calderón-Garcidueñas L, Mora-Tiscareño A, Francolira M, Torres-Jardón R, Peña-Cruz B, Palacios-López C, et al. Exposure to urban air pollution and bone health in clinically healthy six-year-old children. Arh Hig Rada Toksikol 2013;64(1):23-34. 
[15] Prada D, López G, Solleiro-Villavicencio H, Garcia-Cuellar C, Baccarelli AA. Molecular and cellular mechanisms linking air pollution and bone damage. Environ Res 2020;185:109465

[16] Iranian air pollution monitoring system. [cited 2020 Mar 20]. Available from: http://aqms.doe.ir/Home/AQI

[17] Qin G, Wang J, Huo Y, Yan H, Jiang C, Zhou J, et al. Sulfur dioxide inhalation stimulated mitochondrial biogenesis in rat brains. Toxicology 2012;300(1-2):67-74.

[18] Mendes MM, Darling AL, Hart KH, Morse S, Murphy RJ, Lanham-New SA. Impact of high latitude, urban living and ethnicity on 25-hydroxyvitamin D status: A need for multidisciplinary action?. J Steroid Biochem Mol Biol 2019;188:95-102

[19] Bergin MH, Ghoroi C, Dixit D, Schauer JJ, Shindell DT. Large reductions in solar energy production due to dust and particulate air pollution. Environ Sci Technol Lett 2017;4(8):339-344.

[20] Manicourt DH, Devogelaer JP. Urban tropospheric ozone increases the prevalence of vitamin D deficiency among Belgian postmenopausal women with outdoor activities during summer. J Clin Endocrinol Metab 2018;93(10):38933899.

[21] Agarwal KS, Mughal MZ, Upadhyay P, Berry JL, Mawer EB, Puliyel JM. The impact of atmospheric pollution on vitamin D status of infants and toddlers in Delhi, India. Arch Dis Child 2002;87(2):111-113.

[22] Holick MF. Sunlight and vitamin D for bone health and prevention of autoimmune diseases, cancers, and cardiovascular disease. Am J Clin Nutr 2004;80(6):1678S-1688S.

[23] Bell TD, Demay MB, Burnett-Bowie SA. The biology and pathology of vitamin D control in bone. J Cell Biochem 2010;111(1):7-13.

[24] Al-Bashaireh AM, Haddad LG, Weaver M, Chengguo X, Kelly DL, Yoon S. The effect of tobacco smoking on bone mass: an overview of pathophysiologic mechanisms. J Osteoporos 2018:1206235.

[25] Holick MF, MacLaughlin JA, Clark MB, Holick SA, Potts JT, Anderson RR, et al. Photosynthesis of previtamin D3 in human skin and the physiologic consequences. Sci 1980;210(4466):203-205.

[26] Hluchan SE, Pomerantz K. Ullmann's Encyclopedia of Industrial Chemistry (Calcium and Calcium Alloys). Wiley-VCH; 2000

[27] Rückerl R, Schneider A, Breitner S, Cyrys J, Peters A. Health effects of particulate air pollution: a review of epidemiological evidence. Inhal Toxicol 2011;23(10):555-592.

[28] Smith BJ, Lerner MR, Bu SY, Lucas EA, Hanas JS, Lightfoot SA, et al. Systemic bone loss and induction of coronary vessel disease in a rat model of chronic inflammation. Bone 2006;38(3):378-386.

[29] Simonet WS, Lacey DL, Dunstan CR, Kelley M, Chang MS, R Lüthy, et al. Osteoprotegerin: a novel secreted protein involved in the regulation of bone density. Cell 1997;89(2):309-319.

[30] Lee NK, Sowa H, Hinoi E, Ferron M, Ahn JD, Confavreux C, et al. Endocrine regulation of energy metabolism by the skeleton. Cell 2007;130(3):456-469.

[31] Berger JM, Singh P, Khrimian L, Morgan D, Chowdhury S, Arteaga-Solis E, et al. Mediation of the Acute Stress Response by the Skeleton. Cell Metab 2019;30(5):890-902.e8.

[32] Foucault P, Foucault MH, Kucharewicz B, Bureau F, Alix M, Drosdowsky MA. Value of the study of total alkaline phosphatases and bone isoenzyme in a population of subjects with osteoporosis. Annales de Biologie Clinique 1991;49(9):477-481. 